\title{
Magnitude of stunting and its determinants in children aged 6-59 months among rural residents of Damot Gale district; southern Ethiopia
}

\author{
Lamirot Abera ${ }^{1}$, Tariku Dejene ${ }^{2}$ and Tariku Laelago ${ }^{3^{*}}$
}

\begin{abstract}
Objective: The objective of this study is assessing magnitude of stunting and its predictors among children aged 6-59 months in Damot Gale district, South Ethiopia. Community based cross sectional study was done at Damot Gale district. About 398 children aged 6-59 months were included in the study. Kebele (small administrative unit) and household were chosen by two-phase cluster sample design. Structured questionnaire was used to gather the data. Anthropometric measurement was also used to get the data. SPSS version 20 was used to analysis the data.

Results: About 41.7\% of children were stunted. Children aged 36-47 months [AOR 6.22; 95\% Cl (1.81-21.36)], and 48-59 months [AOR 7.27; 95\% Cl (1.22-43.19)], sex of the child [AOR 20.79; 95\% Cl (7.50-57.65)], birth order [AOR $6.42 ; 95 \% \mathrm{Cl}(1.68-24.48)]$, mother education [AOR 0.06; 95\% Cl (0.02-0.14)], having toilet facility [AOR 0.059; $95 \% \mathrm{Cl}$ (0.02-0.18)], washing hand by soap [AOR 16.21; $95 \% \mathrm{Cl}(5.11-51.4)$ ] and ANC [AOR 0.045; 95\% Cl (0.01-0.13)] were associated with stunting.
\end{abstract}

Keywords: Rural dwellers, Children, Stunting

\section{Introduction}

Malnutrition is one of the most common causes of illness and death among children throughout the world. It has been accountable directly or indirectly for $60 \%$ of the 10.9 million deaths yearly among under-5 children $[1,2]$. Studies conducted in various parts of Ethiopia displayed the magnitude of stunting between 35.4 and $47.6 \%$ [3-7]. In South Ethiopia, 44\% children are stunted [8].

The political and financial circumstances, education, climate, culture, breast-feeding, custom of food are some of the features that affect nutritional status of a given community [9]. Factors that can affect nutritional status of the children could be age $[4,6,7]$, being male child [3, $4]$, mothers education $[7,8]$ and attending antenatal care (ANC) [10-12]. Availing data on stunting level and its

\footnotetext{
*Correspondence: tarikulalago@gmail.com

${ }^{3}$ Department of Health Information Technology, Hossana College of Health Science, P.O. Box 159, Hossana, Ethiopia

Full list of author information is available at the end of the article
}

determinants is important for preparation and employment of interventions that focus on reducing illness and death associated with stunting. Therefore, this paper focused on examining the magnitude and predictors of stunting among children of age 6-59 months in rural parts of Damot Gale.

\section{Main text \\ Methods \\ Study area and study period}

Our study was done in rural part of Damot Gale district. Damot Gale district is located in Wolayita zone, southern Ethiopia. The total areal size of the Damot gale district is $255.54 \mathrm{~km}^{2}$ [13]. Geographically, the district is situated between the coordinate of $6^{\circ} 32^{\prime} 24^{\prime \prime} \mathrm{N}$ and $7^{\circ} 7^{\prime} 30^{\prime \prime} \mathrm{N}$ latitude and $37^{\circ} 44^{\prime} 53^{\prime \prime} \mathrm{E}$ and $37^{\circ} 56^{\prime} 24^{\prime \prime} \mathrm{E}$ of longitude. In 2013, the total predicted population of Damot Gale is 186,687. About 22,069 children aged 6-59 months are 
living in rural parts of the district. The study was conducted in February 2016.

\section{Study design}

Community based cross-sectional.

\section{Study population}

Children aged 6-59 months and their mothers.

\section{Sample size and sampling technique}

The sample size was computed by single population proportion formula.

$$
\mathrm{n}=\frac{\left(\mathrm{Z}_{\alpha / 2}\right)^{2}}{\mathrm{~d}^{2}}[\mathrm{p}(1-\mathrm{p})]
$$

where $\mathrm{n}=$ sample size required, $\mathrm{p}=$ estimated proportion of children aged 6 -59 months with stunting. $\mathrm{z}=\mathrm{Z}$-score associated with appropriately chosen level of confidence, $\mathrm{d}=$ acceptable margin of errors.

To compute the sample size, the prevalence of stunting, $44.1 \%$ was taken from study of south Ethiopia [8]. The margin of error of $5 \%$ and $95 \%$ level of confidence was also considered. Adding 5\% contingency for expected non-response rate, the final sample size became 398 .

A two-phase cluster sampling design was employed. The first sampling element was Kebele (small administrative unit) and the second sampling elements were households $(\mathrm{HH})$ who have children aged 6-59 months along with their mothers. At first stage of sampling, simple random sampling process was employed to select Kebele. Then, the $\mathrm{HH}$ of the designated kebele was gotten from the health extension employees. The number of worthy of being chosen $\mathrm{HH}$ was assigned based on population number using proportional allocation method. In case where, $\mathrm{HH}$ has more than one worthy of being chosen child, one child was designated by lottery system.

\section{Data collection processes, measurements and definitions}

The data collection instrument was set with allusion to the 2011 Ethiopian demographic and health survey (EDHS). It was first set in English, interpreted to wolayia then, re-interpreted back to English to ensure uniformity.

Two days training was given for data collectors and supervisors. Pre-test was made on similar eligible study children from the adjacent enumeration part. Calibrated gauging board was used to measure the height of the children. A recumbent position was used to measure height of the children who cannot stand erected. The child who can stand erected and above 24 months was measured on standup position against calibrated height gauging board. The measurement was taken to the adjacent $0.1 \mathrm{~cm}$. To maintain the quality of data, the investigator and supervisors supervised the data collection area during the entire period of data collection.

Stunting (height for age) was the dependent variable of the study. The independent variables included sociodemographic and economic feature such as a child's age and sex, family size, birth order and interval, $\mathrm{HH}$ income source, marital status, education and occupation of mother. Maternal health feature composed of attending $\mathrm{ANC}$, giving birth at health institution and using contraceptive. Child health features were exclusive breastfeeding, health situation, existence of diarrhea, and vaccination, eating with older sibling. On environmental health situation: hand washing, cleanliness during feeding and food preparation, presence of latrine and sources of water were collected. Stunted was defined based on Z-score below -2 standard deviations of the WHO median reference for height-for-age.

\section{Statistical analysis}

Data were entered and analyzed by SPSS version 20 . Age of child, sex, and height were entered into World Health Organization (WHO) Anthro software to create measurement indices of height-for-age. Data recorded in WHO Anthro was transferred to SPSS version 20. Binary logistic regression analysis was carried out at two levels. First, a bivariate analysis was done to assess the predictors of stunting by explanatory variables. Secondly, those predictor variables, which are significantly associated with the outcome variable at 0.2 and less level of significance in the bivariate analyses, were examined at multivariate logistic regression. To display strength of association between dependent and independent variables, odds ratio at $95 \%$ CI were computed. Variables with $\mathrm{p}$-value $<0.05$ in multivariate analyses were used to state statistical significance.

\section{Results}

\section{Socio-demographic and economic features}

The study comprised 398 children aged 6-59 months. About $33.7 \%$ of children were in the age range of 36-47 months. Regarding sex of the children, $43 \%$ were males. The big percentage $(91.7 \%)$ of mothers were currently married. Above half of the mothers $(56 \%)$ were illiterate. Forty-six (11.6\%) of women had secondary and above secondary education level. Agriculture was the leading source of $\mathrm{HH}$ income for 340 (85.4\%) respondents. First births constituted 56 (14.1\%) and 5+ birth orders constituted 155 (38.9\%). About 295 (71.1\%) HH has one child. About $214(53.8 \%) \mathrm{HH}$ agricultural land was less than half a hectare. The main source of water for 
HH was public pipe, 287 (72.1\%). Concerning about toilet facilities, 358 (90\%) HH had latrine. Non-improved pit latrine was used in 276 (77.1\%) HH (Table 1) [14].
Maternal and child health utilization

About 167 (42\%) children aged less than 6 months were not exclusively breastfed. Three hundred seven $(81 \%)$

Table 1 Socio demographic and economic features of the respondents, Damot Gale, 2016

\begin{tabular}{|c|c|c|c|}
\hline Features $(n=398)$ & Categories & Number & Percent \\
\hline \multirow[t]{5}{*}{ Age of child in months } & $6-11$ & 36 & 9.0 \\
\hline & $12-23$ & 113 & 28.4 \\
\hline & $24-35$ & 79 & 19.8 \\
\hline & $36-47$ & 134 & 33.7 \\
\hline & $48-59$ & 36 & 9.0 \\
\hline \multirow[t]{2}{*}{ Child's sex } & Male & 171 & 43.0 \\
\hline & Female & 227 & 57.0 \\
\hline \multirow[t]{4}{*}{ Current marital status of mothers } & Married & 365 & 91.7 \\
\hline & Separated & 17 & 4.3 \\
\hline & Divorced & 2 & 0.5 \\
\hline & Widowed & 14 & 3.5 \\
\hline \multirow[t]{3}{*}{ Educational status of mother } & Illiterate & 223 & 56.0 \\
\hline & Primary & 129 & 32.4 \\
\hline & Secondary and above & 46 & 11.6 \\
\hline \multirow[t]{3}{*}{ Source of HH income } & Agriculture & 340 & 85.4 \\
\hline & Off-farm & 31 & 7.8 \\
\hline & Non-farm & 27 & 6.8 \\
\hline \multirow[t]{4}{*}{ Birth order } & One & 56 & 14.1 \\
\hline & Two to three & 73 & 18.3 \\
\hline & Four to five & 114 & 28.6 \\
\hline & Above five & 155 & 38.9 \\
\hline \multirow[t]{5}{*}{ Birth interval in months } & First birth & 56 & 14.1 \\
\hline & Less than 24 & 127 & 31.9 \\
\hline & $24-35$ & 107 & 26.9 \\
\hline & $36-47$ & 61 & 15.3 \\
\hline & 48 and above & 47 & 11.8 \\
\hline \multirow[t]{2}{*}{ Number of children aged 6-59 months in $\mathrm{HH}$} & One & 295 & 74.1 \\
\hline & Two to three & 103 & 25.9 \\
\hline \multirow[t]{3}{*}{ Family size } & Two to four & 75 & 18.8 \\
\hline & Five to eight & 284 & 71.4 \\
\hline & Nine to eleven & 39 & 9.8 \\
\hline \multirow[t]{4}{*}{ Agricultural land size in hectares } & Less than half & 214 & 53.8 \\
\hline & Half to one & 116 & 29.1 \\
\hline & Greater than one and less than two & 58 & 14.6 \\
\hline & Greater than two & 10 & 2.5 \\
\hline \multirow{4}{*}{$\begin{array}{l}\text { Situations child's mother routinely wash her hand by using } \\
\text { soap }\end{array}$} & Before nourishing the baby & 90 & 21.9 \\
\hline & Before breast nursing & 37 & 9.0 \\
\hline & After washing baby's bottom & 160 & 38.9 \\
\hline & Before food preparation & 124 & 30.2 \\
\hline \multirow[t]{2}{*}{ Type of latrine } & Pit & 276 & 77.1 \\
\hline & Improved & 82 & 22.9 \\
\hline \multirow[t]{3}{*}{ Source of water for drinking } & River & 31 & 7.8 \\
\hline & Public pipe & 287 & 72.1 \\
\hline & Spring & 80 & 20.1 \\
\hline
\end{tabular}


children were fully vaccinated. less than half, 141 (35.4\%) of mothers did not received ANC service. Only 109 (27.4\%) of women gave birth at health institution. More than half, 235 (59\%) mothers used contraceptive. Fifty-six (14\%) children had diarrhoea (Table 2) [14].

\section{Magnitude of stunting}

The study revealed that $41.7 \%$ of children were stunted.

\section{Predictors of stunting}

On multivariate analysis, age of child, sex, birth order, mother education, washing hand, availability of latrine and ANC were associated with stunting. Children aged 36-47 months and 48-59 months were 6.22 and 7.27 times more probable to be affected by stunting as compared to children whose age was 6-11 months [AOR 6.22; 95\% CI (1.81-21.36)], AOR 7.27; 95\% CI (1.2243.19). Male children were 20.8 times more to be affected by stunting as compared to female children [AOR 20.79; 95\% CI (7.50-57.65)]. Birth order above five were found 6.42 times more probable to be stunted than first born children [AOR 6.42; 95\% CI (1.68-24.48)]. Children whose mothers have a primary education were $94 \%$ less probable to have stunted children than illiterate mothers [AOR 0.06; 95\% CI (0.02-0.14)]. Having toilet facility reduced the chance of stunting by $94 \%$ [AOR $0.059 ; 95 \%$ CI (0.02-0.18)].

Children who did not usually wash their hand by using soap before eating and after defecating were 16.21 times more to be stunted than children who did [AOR 16.21;

Table 2 Maternal and child health service features, Damot Gale, 2016

\begin{tabular}{|c|c|c|c|}
\hline Features & Categories & Number & Percent \\
\hline \multirow[t]{2}{*}{ Fully vaccinated } & No & 72 & 19.0 \\
\hline & Yes & 307 & 81.0 \\
\hline \multirow[t]{2}{*}{ Exclusive breast feeding } & No & 167 & 42.0 \\
\hline & Yes & 231 & 58.0 \\
\hline \multirow[t]{2}{*}{ Eat with older sibling } & No & 364 & 91.5 \\
\hline & Yes & 34 & 8.5 \\
\hline \multirow[t]{2}{*}{ Followed ANC } & No & 141 & 35.4 \\
\hline & Yes & 257 & 64.6 \\
\hline \multirow[t]{2}{*}{ Place of delivery } & Health institution & 109 & 27.4 \\
\hline & Home & 289 & 72.6 \\
\hline \multirow[t]{2}{*}{ Used contraceptive } & No & 235 & 59.0 \\
\hline & Yes & 163 & 41.0 \\
\hline \multirow[t]{3}{*}{ Children health situation } & Always sick & 20 & 5.1 \\
\hline & Sometimes sick & 108 & 27.1 \\
\hline & Healthy & 270 & 67.8 \\
\hline \multirow[t]{2}{*}{ Diarrheal happen } & No & 342 & 86.0 \\
\hline & Yes & 56 & 14.0 \\
\hline
\end{tabular}

95\% CI (5.11-51.40)]. Mothers followed ANC had 95.5\% less probable to have stunted children than mothers did not [AOR 0.04; 95\% CI (0.01-0.13)] (Table 3).

\section{Discussion}

This study tried to assess magnitude of stunting and associated factor among 6-59 months old children. Based on the findings the study, the magnitude of stunting was $41.7 \%$. This is somewhat comparable with study of EDHS and Hawassa Zuria, which presented stunting as 44.1 and $45.8 \%$, respectively $[5,8]$. Generally, magnitude of stunting in the study area are higher compared to the cutoff point stated by Federal Minister of Health [15]. The magnitude of stunting in current study is lower than study of Oromia region, which displayed $47.6 \%$ of children were stunted [6]. But, it is higher than study conducted in Somalia region and Hossana town, which showed 34.4 and $35.5 \%$ of children were stunted, respectively [3, 7]. The difference may be due to difference in study setting, difference in child feeding habit in rural and urban settings.

The result of the present study showed that child's age is one of determinant feature of stunting. This result is in line with studies conducted in Ethiopia and other developing countries $[6,7,16,17]$.

The finding of this study revealed that male children were more affected by stunting as compared to female children. This is consistent with results of West Gojam and other studies $[3,18,19]$.

The current study showed that the risk of stunting increases when birth order was above 5 . This finding agrees with study conducted in Uganda [20]. It also aggresses with study conducted in Hossana [7]. The positive significant relationship between child birth order and occurrence of stunting could be explained by the fact that the family pot is shared among a huge number of people in the $\mathrm{HH}$, thus inadequate dietary can be in taken by children for a prolonged period and eventually the manifestation of chronic malnutrition starts [21]. The current study is incomparable with study done in Ethiopia, which showed first birth order were found to be at a considerably higher risk of stunting than higher birth order [16].

Children whose mothers have a primary level of education had a significantly reduced likelihood of stunting as compared to illiterate mothers. This is consistent with study done in Hossana and by EDHS [7, 8]. This may be due to education is one of the most important resources that enable women to provide appropriate care for their children. Educating women is believed to exert an impact on health and nutritional status of children since it provides the mother with the necessary skills for childcare, increase awareness of nutritional needs and preference of modern health facilities. 
Table 3 Predictors of stunting, Damot Gale, 2016

\begin{tabular}{|c|c|c|c|c|c|}
\hline \multirow[t]{2}{*}{ Features } & \multirow[t]{2}{*}{ Categories } & \multicolumn{4}{|l|}{ Stunting } \\
\hline & & No $(N, \%)$ & Yes (N, \%) & COR at $95 \%$ & AOR at $95 \% \mathrm{Cl}$ \\
\hline \multirow[t]{5}{*}{ Age of child in months } & $6-11$ & $30(12.9)$ & $6(3.6)$ & 1.00 & 1.00 \\
\hline & $12-23$ & $83(35.8)$ & $30(18.1)$ & $1.28(0.318-5.21)$ & $1.22(0.34-4.42)$ \\
\hline & $24-35$ & $52(22.4)$ & $27(16.3)$ & $6.24(1.18-32.78)^{*}$ & $3.96(0.91-17.33)$ \\
\hline & $36-47$ & $46(19.8)$ & $88(53.0)$ & $9.46(2.08-43.1)^{*}$ & $6.22(1.81-21.36)^{*}$ \\
\hline & $48-59$ & $21(9.1)$ & $15(9.0)$ & $18.25(2.58-128.8)^{*}$ & $7.27(1.22-43.19)^{* *}$ \\
\hline \multirow[t]{2}{*}{ Sex of child } & Female & $171(73.7)$ & $56(33.7)$ & 1.00 & 1.00 \\
\hline & Male & $61(26.3)$ & $110(66.3)$ & $32.38(9.89-106.11)^{*}$ & $20.80(7.50-57.65)^{*}$ \\
\hline \multirow[t]{4}{*}{ Birth orders } & First child & $45(19.4)$ & $11(6.6)$ & 1.00 & 1.00 \\
\hline & $2-3$ & $62(26.7)$ & $11(6.6)$ & $0.894(0.16-4.99)$ & $0.70(0.14-3.38)$ \\
\hline & $4-5$ & $72(31.1)$ & $42(25.3)$ & $1.43(0.366-5.56)$ & $1.28(0.36-4.51)$ \\
\hline & $5+$ & $53(22.8)$ & $102(61.5)$ & $8.12(1.93-34.19)^{*}$ & $6.42(1.68-24.48)^{*}$ \\
\hline \multirow[t]{3}{*}{ Educational status of mother } & Illiterate & $75(32.4)$ & $148(89.2)$ & 1.00 & 1.00 \\
\hline & Primary & $120(51.7)$ & $9(5.4)$ & $0.06(0.02-0.17)^{*}$ & $0.06(0.02-0.14)^{*}$ \\
\hline & Secondary and above & $37(15.9)$ & $9(5.4)$ & $0.34(0.06-1.98)$ & $0.32(0.06-1.55)$ \\
\hline \multirow[t]{2}{*}{ Availability of latrine } & No & $6(2.6)$ & $36(21.7)$ & 1.00 & 1.00 \\
\hline & Yes & $226(97.4)$ & $130(78.3)$ & $0.028(0.01-0.14)^{*}$ & $0.06(0.02-0.18)^{*}$ \\
\hline \multirow{4}{*}{$\begin{array}{l}\text { Child usually wash her/his hand's } \\
\text { by using soap }\end{array}$} & Before eating & $96(41.4)$ & $40(24.1)$ & 1.00 & 1.00 \\
\hline & After defecating & $32(13.8)$ & $14(8.4)$ & $1.12(0.197-6.33)$ & $0.95(0.203-4.45)$ \\
\hline & Both & $39(16.8)$ & $4(2.4)$ & $0.12(0.025-0.621)^{*}$ & $0.18(0.05-0.72)^{* *}$ \\
\hline & None of the above & $65(28.0)$ & $108(65.1)$ & $24.89(7.13-86.84)^{*}$ & $16.21(5.11-51.4)^{*}$ \\
\hline \multirow[t]{2}{*}{ Following ANC } & No & $36(15.5)$ & $105(63.3)$ & 1.00 & 1.00 \\
\hline & Yes & $196(84.5)$ & $61(36.7)$ & $0.11(0.012-0.795)^{*}$ & $0.045(0.01-0.135)^{*}$ \\
\hline
\end{tabular}

${ }^{*}$ p-value $<0.2,{ }^{* *}$-value $<0.01,{ }^{* * *} p$-value $<0.05$

Having toilet facility reduced the chance of stunting. This is in line with the results of other study [20]. Another study conducted in Nigeria also revealed that having toilet has a significant negative effect on the chance of stunting [19]. The reason for the above studies can be explained by the following sentences. Unfavorable health environment can increase the probability of infectious diseases and indirectly can cause certain types of malnutrition.

Children who did not usually wash their hand by using soap before eating and after defecating were more probable to have had stunting than children who did. This is not surprising since there is a relationship between sanitation and infectious diseases. Study conducted on children revealed proper hand washing before meals and after defecating, could lower exposure to germs. This can lessen the chances of illness and chronic inflammation leading to better nutrition intake, more energy available for growth and development [22].

Following ANC was associated with stunting. This is consistent with other studies conducted in Ethiopia and other developing countries [10-12].

The current study shows that stunting is a common among children 6-59 months age. Child's sex, birth order, following ANC, age of child, mothers' education, washing hand, and availability of latrine were predictors of stunting.

Equivalent consideration should be given during feeding both male and female children. Promotion of ANC should be strengthened especially in rural setting. The health extension workers and other concerned body should do more on increasing availability of latrine and hand washing facilities. Health education on importance of hand washing should be strengthened at community level. Educational difference has an impact on child stunting, so due attention should be given to promote and increase education coverage of females.

\section{Limitation of the study}

Questions that required a good memory were vulnerable to recall bias.

As the study is cross-sectional, it neither characterises seasonal difference of nutritional outcomes nor creates causal association.

\section{Abbreviations}

ANC: antenatal care; EDHS: Ethiopian demographic health survey; $\mathrm{HH}$ : households; WHO: World Health Organization. 


\section{Authors' contributions}

LA wrote the proposal, participated in data collection, analysed the data and drafted the paper. TD approved the proposal, participated in data analysis and revised subsequent draft of the paper. TL participated in data analysis and reviewed subsequent drafts of the paper. All authors read and approved the final manuscript.

\section{Author details}

${ }^{1}$ Central Statics Agency, Addis Ababa, Ethiopia. ${ }^{2}$ Department of Population Studies, Addis Ababa University, Addis Ababa, Ethiopia. ${ }^{3}$ Department of Health Information Technology, Hossana College of Health Science, P.O. Box 159, Hossana, Ethiopia.

\section{Acknowledgements \\ Not applicable.}

\section{Competing interests}

The authors declare that they have no competing interests.

\section{Availability of data and materials}

The datasets during and/or analysed during the current study available from the corresponding author on reasonable request.

\section{Consent for publication}

Not applicable.

\section{Ethics approval and consent to participate}

Ethical clearance was obtained from Addis Ababa University, College of Development Studies. Permission for conducting the study was obtained from officials of the district. Each respondent was informed about the objective of the study. Verbal consent was secured from children's parents or legal guardian. The verbal (non-written) consent was obtained because written consent needed a certain level of education to read and sign the consent. Participants had the right to refrain from answering some questions or withdraw from the study process at any time.

\section{Funding}

Not applicable.

\section{Publisher's Note}

Springer Nature remains neutral with regard to jurisdictional claims in published maps and institutional affiliations.

Received: 1 March 2018 Accepted: 1 August 2018

Published online: 03 August 2018

\section{References}

1. WHO. Management of severe malnutrition: a manual for physicians and other senior health workers. Geneva: WHO; 1999.

2. WHO. Global strategy for infant and young child feeding. Geneva: WHO; 2002.

3. Demissie S, Worku A. Magnitude and factors associated with malnutrition in children 6-59 months of age in pastoral community of Dollo Ado district, Somali region, Ethiopia. Sci J Public Health. 2013;1(4):175-83. https://doi.org/10.11648/j.sjph.20130104.1
4. Yalew BM. Prevalence of malnutrition and associated factors among children age 6-59 months at Lalibela town administration, North Wollo Zone, Anrs, Northern Ethiopia. J Nutr Disord Ther. 2014;4:132. https://doi. org/10.4172/2161-0509.1000132.

5. Danbe D, Taye A. Nutritonal status of under-five children in Hawassa Zuria district, southern Ethiopia. Am J Health Res. 2015;3(5):286-92.

6. Mengistu K, Alemu K, Destaw B. Prevalence of malnutrition and associated factors among children aged 6-59 months at Hidabu Abote district, North Shewa, Oromia Regional State. J Nutr Disord Ther. 2013;11:001. https://doi.org/10.4172/2161-0509.T1-001.

7. Moges B, Feleke A, Meseret S, Doyore F. Magnitude of stunting and associated factor among 6-59 months old children in Hossana town, southern Ethiopia. J Clin Res Bioeth. 2015;6:207.

8. Central Statistical Authority. Demographic and health survey 2011. Addis Ababa, Calverton: Central Statistical Authority and ICF International; 2012

9. Morris SS, Cogill B, Uauy R. Effective international action against undernutrition: why has it proven so difficult and what can be done to accelerate progress? Lancet. 2008;371:608-21.

10. Yimer G. Malnutrition among children in southern Ethiopia: level and risk factors. Ethiop J Health Dev. 2000;14(3):283-92.

11. Hamel C, Enne J, Omer K, Ayara N, Yarima Y, Cockcroft A et al. Childhood malnutrition is associated with maternal care during pregnancy and childbirth: a cross-sectional study in Bauchi and Cress River States, Nigeria. J Public Health Res. 2015;4:408:58-64.

12. Girma W, Genebo T. Determinants of nutritional status of women and children in Ethiopia. Addis Ababa: Ethiopia Health and Nutritional Research Institute; 2002

13. Central Statistics Agency. Population and housing census report at national level. Addis Ababa: Central Statistical Authority; 2010.

14. Abera L, Dejene T, Laelago T. Prevalence of malnutrition and associated factors in children aged 6-59 months among rural dwellers of damot gale district, south Ethiopia: community based cross sectional study. Int J Equity Health. 2017;16:111. https://doi.org/10.1186/s12939-017-0608-9.

15. $\mathrm{FMOH}$. Health sector development programme IV first year annual performance report. Ethiopia: $\mathrm{FMOH} ; 2003$.

16. Asres $\mathrm{G}$, Eidelman A. Nutritional assessment of Ethiopian Beta-Israel Children: a cross-sectional survey. Breastfeed Med. 2011;6:171-6.

17. Olack B, Burke H, Cosmas L, Bamrah S, Dooling K. Nutritional status of under-five children living in an informal urban settlement in Nairobi. Kenya J Health Popul Nutr. 2011;29(4):357-63.

18. Badake Q, Maina I, Mboganie M, Muchemi G, Kihoro E, Chelimo E, Mutea K. Nutritional status of children under five years and associated factors in Mbeere, South district Kenya. Afr Crop Sci J. 2014;22:799-806.

19. Olanrewaju R, lyabo F, Bamidele S, Eunice F. Prevalence and determinants of malnutrition among under-five children of farming households in Kwara State, Nigeria. J Agric Sci. 2011;3:173-81.

20. Gilbert $\mathrm{H}$. Determinants of malnutrition among under-five children in Nakaseke and Nakasongola districts, Uganda. BMC Pediatrics. 2015:15:134.

21. Macharia C, Kogi-Makau W, Muroki NM. A comparative study on the nutritional status of children (6-59 months) in a world vision project area and a non-project area in kathonzweni Division, Makueni district, Kenya. Afr J Food Agric Nutr Dev (AJFAND). 2005:5(1).

22. Humphrey J. Child undernutrition, tropical enteropathy, toilets, and handwashing. Lancet. 2009;374:1032-5. 